\title{
ANTROPOLOGÍA Y FENOMENOLOGÍA EN NICOLÁS GÓMEZ DÁVILA
}

\author{
ENVER TORREGROZA LARA \\ Universidad del Rosario
}

\begin{abstract}
RESUMEN: El propósito del artículo es ofrecer una aproximación a la filosofía del pensador bogotano Nicolás Gómez Dávila a partir de una interpretación de su libro Textos I, publicado en 1959. En el artículo se defiende que los diez ensayos aparentemente dispersos de Textos / se articulan temáticamente en torno a los grandes problemas de la antropología filosófica, y metódicamente, pueden ser descritos como ejercicios fenomenológicos. Se propone para ello una hermenéutica filosófica que distingue diferentes momentos de pensamiento en la obra del filósofo colombiano y que toma distancia de la pretensión de encontrar un sistema total de pensamiento en una obra intencionalmente fragmentaria.
\end{abstract}

PALABRAS CLAVE: antropología filosófica; fenomenología; filosofía colombiana; Nicolás Gómez Dávila.

\section{Anthropology and Phenomenology in Nicolás Gómez Dávila}

ABSTRACT: The aim of the article is to show a new interpretation of Nicolás Gómez Dávila's philosophy by means of an analysis of his early work Textos $I$. In the article it is demonstrated that the ten essays of this book, apparently dispersed, are connected thematically around the big questions of philosophical anthropology. They also can be described as phenomenological exercises from the methodological point of view. A philosophical hermeneutic of the Dávila's work, attending different moments of his philosophy and rejecting the will to find a total system of thinking in a fragmented work, must be put forward.

KEY WORDS: philosophical anthropology; phenomenology; colombian philosophy; Nicolás Gómez Dávila.

\section{Gómez DÁvila como PRoblema hermenéUtico ${ }^{1}$}

Muchas cosas —o quizá más bien pocas, repetidas varias veces- se han dicho sobre el filósofo colombiano Nicolás Gómez Dávila (Bogotá 1913-1994), siendo la mayoría de ellas caracterizaciones generales y curiosas de un personaje histórico sui generis, o consideraciones sobre la forma de ser de un escritor genial y deslumbrante, que omitiendo los argumentos que sostendrían sus ideas, escribe aforismos tan diáfanos como inapresables en una sola sentada. La reducida literatura especializada sobre la obra del pensador bogotano ha repetido una serie de tópicos que ya están comenzando a correr el peligro de volverse estigmas o estereotipos que podrían oscurecer la interpretación.

Tales tópicos incluyen la incomodidad manifiesta de algunos lectores ante las chocantes características de un autor colombiano que no encaja en los moldes habituales del «intelectual latinoamericano», sobre todo por su imagen

1 El presente artículo es un producto del proyecto de investigación «Filosofía política en Colombia», desarrollado en el Grupo de investigación en Estudios Políticos e Internacionales de la Universidad del Rosario (Colombia). 
de «conservador», «aristocrático» y «reaccionario» —siendo este último el único apelativo utilizado programáticamente por el autor para referirse a su propia obra y que el mainstream intelectual liberal no soporta con facilidad cuando se ve obligado a admirar la profundidad del escritor bogotano- ${ }^{2}$. Otros tópicos son las preguntas habituales sobre la razón de ser de su estilo breve y fragmentario que la mayoría insiste en llamar «aforistico» ${ }^{3}$ y, finalmente, la naturaleza del «texto implícito» al que hacen referencia los aparentemente parcos y enigmáticos títulos de sus libros más divulgados.

En el presente artículo se dejan de lado tales preocupaciones queriendo poner en práctica más bien un sencillo principio de lectura. Se trata aquí de abrir aquella puerta para la interpretación filosófica que se cierra cada vez que, queriendo dar cuenta del pensamiento de Gómez Dávila, alguien habla de la totalidad de su obra, etiquetando o clasificando un pensamiento vivo con fórmulas lapidarias, asociadas a la imagen prejuiciosa del «autor».

Por ejemplo, afirmar que Gómez Dávila es un «católico» no agota en absoluto la interpretación de su polifacético ejercicio de escritura, sino que abre la puerta a una problematización de lo que podemos entender por "católico»: Gómez Dávila nos demanda seriamente a pensar en ello. Tales adjetivaciones no aportarían mayor cosa si reducen a un prejuicio la comprensión de una obra rica en cuestionamientos. Una lectura que se afane en clasificarla, ubicarla o estigmatizarla mediante un único concepto-y a menudo los tres procedimientos son el mismo-- está pasando por alto uno de los acontecimientos principales de la obra de Gómez Dávila: la problematización constante de lo que puedan significar las categorías con las que se la describe.

Para decirlo de otra manera, mucho más enfática: es hora de que los estudios gomezdavilianos se arriesguen a trabajar en la forma como el pensador bogotano pone en cuestión muchos de nuestros conceptos, en vez de intentar entenderlo a partir de la supuesta evidencia que tales conceptos representan. Hay que ver en su tratamiento de lo «reaccionario» y lo «católico», así como

2 No hay que comprender a Gómez Dávila a la luz del concepto corriente de reaccionario, sino más bien intentar iluminar el concepto a partir del sentido que el filósofo colombiano le otorga. «Reaccionario» es el único apelativo que Gómez Dávila utiliza programáticamente para entender su propia obra, prefiriendo siempre la expresión «reaccionario auténtico», a la que le dedica todo un artículo («El reaccionario auténtico» en: Revista de la Universidad de Antioquia, No. 240, 1995, pp. 16-19). Gómez Dávila aplica el adjetivo de reaccionario a su modo de pensar filosófico, tanto en sentido metodológico como propositivo, en varios lugares de su obra y no lo usa como mero mote político. Hay que hablar por tanto con Gómez Dávila de un pensamiento reaccionario como una propuesta filosófica integral.

3 El carácter fragmentario del estilo de Gómez Dávila responde a una decisión filosófica que tiene a su vez una dimensión ética-estética: «si es menester, que la lucidez del orgullo nos conduzca a la humildad y que el amor a las palabras nos entregue al silencio» (Gómez DáviLA, N., Notas, Villegas, Bogotá, 2003, p. 47) y una dimensión ontológica: «el discurso tiende a ocultar las rupturas del ser, el fragmento es la expresión del pensamiento honrado» (Gómez Dávila, N., Nuevos escolios a un texto implícito, Villegas, Bogotá, 2005, Tomo II, p. 203) y «el fragmento es el medio de expresión del que aprendió que el hombre vive entre fragmentos» (Id., p. 87). 
de «Dios», la «modernidad» y cualquier otra cantidad importante de temas recurrentes en su obra, hondas preocupaciones filosóficas y no simples tesis rígidas que fungirían de armas para acallar interrogaciones profundas.

La obra de Nicolás Gómez Dávila es un ejercicio de creación, en continua transformación, mediante el cual el filósofo colombiano habría afrontado, al igual que Goethe, los dramas de una existencia consciente ${ }^{4}$. Su trabajo filosófico es también una reacción vital a un mundo histórico, el de la modernidad, cuya característica fundamental es la amenaza del nihilismo. En combate abierto con las poderosas fuerzas que lo amenazan, el bogotano esgrime los fragmentos de un naufragio como tablas temporales de flotación, a sabiendas de que estas puntiagudas lanzas de pensamiento, por más agudas y brillantes que sean, no son sino modestos gestos efímeros, instantes de luz que por sí mismos no orientan ni salvan.

\section{TeXtos I EN La obra de Gómez DÁvila}

En el conjunto de la producción escrita de Nicolás Gómez Dávila, el pequeño libro publicado con el título genérico Textos I se destaca por la forma como abiertamente desarrolla argumentos y reflexiones filosóficas que ponen al pensamiento de Gómez Dávila en diálogo directo con la tradición filosófica occidental y en particular con la filosofía moderna y contemporánea.

Textos I, fue publicado en México en $1959^{5}$, en una edición privada y sólo se dio a conocer ampliamente al público tras la redición de Villegas de 2002 en Bogotá y luego la de Atalanta en Madrid en 2010. Gómez Dávila nunca publicó Textos II o algo semejante, lo que recuerda el carácter ensayístico, casi experimental, de buena parte de su obra; una suerte de work in progress ${ }^{6}$.

Textos I se ubica, cronológicamente hablando, en los que podríamos llamar la «primera etapa» del trabajo filosófico gomezdaviliano, a medio camino entre su primera obra, que bajo el título de Notas (de 1954) también fue de publicación privada, y la serie de los más famosos Escolios, publicados abiertamente después en Colombia (en 1977, 1986 y 1992). Este dato de ubicación temporal permite lanzar una primera hipótesis sobre la transformación histórica del

4 Torregroza, E., La nave que somos: hacia una filosofía del sentido del hombre. Pontificia Universidad Javeriana, Bogotá, 2014, pp. 234-236 y pág. 308.

5 Como se indica la reedición de Villegas: «La primera edición de Textos I fue realizada en 1959 por su autor, con carácter limitado y no comercial» (Gómez Dávila, N., Textos I, Villegas, Bogotá, 2002, p. 7). Franco Volpi, quien colaboró en esta reedición con don Benjamín Villegas y doña Rosa Emilia Gómez - hija de don Nicolás y principal amanuense y responsable de la divulgación de su obra-, menciona los datos bibliográficos de la primera edición de textos así «Textos I, Bogotá, Editorial Voluntad, 1959» (VolPI, F., Nicolás Gómez Dávila. El solitario de Dios, Villegas, Bogotá, 2005, p. 22). Citamos de aquí en adelante la edición de Villegas.

6 Por ese motivo considero un error el título simplificado «Textos» de la edición española de Atalanta, pues borra un elemento clave de comprensión del proceso de escritura del filósofo colombiano. 
pensamiento de Gómez Dávila, que no hay por qué entenderla en los siempre dudosos términos de una «evolución» o de «maduración».

No es necesario para entender a Gómez Dávila asumir la postura hermenéutica de $\operatorname{Hoyos}^{7}$ que ve en los escolios el telos del proceso de escritura iniciado en Notas y Textos $I^{8}$. Serrano Ruiz-Calderón también califica a Notas de «texto preparatorio» o de «mero boceto de una obra posterior» ${ }^{9}$. Ambos se basan sin duda en Volpi cuando afirma que Notas «es un ejercicio preparatorio para ser olvidado» y que Textos $I$ es «una obra interlocutoria, valiosa para seguir de cerca el madurar de los términos y el contenido de las reflexiones filosóficas del autor, pero igualmente inconclusa ${ }^{10}$. Semejante idea, más que una exageración, es un claro error de interpretación, pues parte del supuesto errado de que Notas y Textos I fueron escritos con miras al desarrollo de los escolios posteriores y no por sí mismos.

Los procesos de escritura de Notas, Textos I y los escolios se superponen. Técnicamente, Gómez Dávila estuvo escribiendo escolios desde un comienzo, y eso se percibe también en las primeras obras, donde prácticamente cada oración tiene la fuerza, la contundencia y la capacidad de síntesis de un escolio ${ }^{11}$. Si Gómez Dávila escribió textos transitorios "para ser olvidados», estos a fin de cuentas habrían sido todos: "Yo carezco de opiniones, sólo tengo breves ideas, transitorias y fugaces, más parecidas a las posadas destartaladas donde descansamos una noche que a las mansiones espléndidas, donde no sabemos bien si moramos, o si somos prisioneros de su misma magnificencia» ${ }^{12}$.

Textos I posee por supuesto características que lo distinguen de las otras obras de Gómez Dávila. En Notas asistimos a un ejercicio rico en creatividad, al desarrollo de un pensamiento que se gesta en una escritura fluída y sin tapujos. En los Escolios se condensan con agudeza las ideas y los argumentos en frases puntillosas, cargadas o ligeras, meditabundas o juguetonas, sin abandonar nunca totalmente la ironía. En Textos I nos encontramos con ensayos en los que se despliega una argumentación filosófica que oscila entre el rigor lógico y la precisión estilística, sin renunciar al fragmento.

7 Hoyos, G., «Don Nicolás Gómez Dávila, pensador en español y reaccionario auténtico» en: Arbor, No. 734, 2008, pp. 1085-1100.

8 Mejía, J. F., «Diálogo entre un demócrata y un reaccionario: Guillermo Hoyos Vásquez y su lectura fenomenológica de Nicolás Gómez Dávila» en: Universitas Philosophica, No. 61, 2013, p. 105.

9 Serrano Ruiz-Calderón, J. M., "Gnosticismo y religión democrática» en: Anuario de Derecho Eclesiástico del Estado, XXIX, 2013, p. 366.

10 Volpi, F., Nicolás..., o. c., pág. 22. Ver también: VolPI, F., «Entre pocas palabras» en: Paradoxa. Revista de Filosofía, No. 14, 2007, p. 9.

${ }_{11}$ Mi esposa argumenta que Gómez Dávila «sólo escribió escolios desde un principio, sólo que algunos son más largos». Creo que tiene razón. Todo escolio no es sino un ensayo: «aquí no intento ofrecer sino esbozos de ideas, leves gestos hacia ellas» (Gómez Dávila, N., Notas, o.c., p. 13). «Las proclamo de nula importancia, y, por eso, notas, glosas, escolios; es decir, la expresión verbal más discreta y más vecina del silencio» (Ib., pág. 17).

$12 \quad I b .$, pág. 12. 
No es necesario sucumbir a la idea formulada ligeramente por Volpi de que en Textos $I$ asistimos a una exposición que tiende al tratado o al sistema, al tratarse de una prosa «contínua» ${ }^{13}$. Desde el comienzo Gómez Dávila cultivó un tipo de pensamiento que atiende cuidadosamente a su forma y que por ello mismo deposita buena parte del peso de su argumentación en la forma como se dicen las cosas - lo que es normal en filosofía, sin importar el estilo- Como se expondrá a continuación en este artículo, la forma de pensar y de escribir en Textos I se distancia programáticamente del tratado o del sistema, lo que no significa que no se pueda poner al descubierto una estructura. Si en ocasiones Gómez Dávila parece jugar al sistema se trata justamente de eso: un juego ${ }^{14}$.

En Gómez Dávila asistimos al despliegue de un verdadero «arte de escribir», en el sentido straussiano del término ${ }^{15}$. Los escolios no son necesariamente la obra «acabada» y «pura» de Gómez Dávila pues en ellos también había juego: por ejemplo, el arte de citar sin citar, como ha afirmado Michäel Rabier ${ }^{16}$.

Por principio metodológico, y para producir ciertos efectos hermenéuticos, vale intentar hablar de la filosofía de Notas como si fuese una distinta de la de Textos $I$, distintas éstas a su vez de las que surgen en cada uno de los tomos de los Escolios, dentro de los cuales no cuesta trabajo descubrir variaciones notables. En un pensador agudo como Gómez Dávila, incluso cada frase podría ser una filosofía, si es que nos atrevemos a jugar con esta hipérbole como mecanismo de lectura metodológicamente deconstructiva, que produciría el rendimiento hermenéutico necesario para compensar las lecturas «totalizantes».

En el presente artículo se apuesta más bien por una interpretación de Textos I que no pretenda descubrir ni al «mejor» Gómez Dávila ni al «verdadero» Gómez Dávila, detras de ese movimiento particular de su pensamiento que fueron los ensayos publicados en 1959. Con este tipo de lectura no pretendemos por tanto resolver los enigmas que plantean sus silencios, su parquedad o sus contradicciones, ni negar sus variaciones en la aproximación filosófica a los problemas. Así como no es necesaria la lectura teleológica, querer salvar a Gómez Dávila de las

13 Volpi, F., Nicolás..., o. c., pág. 22.

14 Gómez Dávila lo reconoce abiertamente al inicio del sexto ensayo de Textos I (pág. 56): «Este parcial intento es artificio de un pensamiento reaccionario. Morada pasajera de un huésped obstinado. No inicio catequización alguna ni ofrezco recetarios prácticos. Ambiciono, tan solo, trazar una curva límpida.// Tarea ociosa. Lucidez estéril. Pero los textos reaccionarios no son más que estelas conminatorias entre escombros.»

15 Rabier, M., «La cuestión literaria en la obra de Nicolás Gómez Dávila» en: Perífrasis, No. 10,2014 , pp. 25-30.

$16 I b .$, pp. 32-33. Sobre la cuestión del arte de citar sin citar al estilo de Montaigne (los «latrocinios» o plagios conscientes con finalidad irónica) como clave para la interpretación de los escolios de Gómez Dávila ver también: Billé, PH., ed., Studia daviliana, La Croix Comtesse: edición del autor, 2003; ABAD Torres, A., Pensar lo implícito: en torno a Gómez Dávila, CRIE, Pereira, 2008, p. 144; RABIER, M., «Biblioteca gomezdaviliana: las fuentes bibliográficas del pensamiento de Nicolás Gómez Dávila» en: Revista interamericana de bibliotecología, Vol. 36, no. 3, 2013, p. 246. Al respecto Gómez Dávila afirmaba: «Evitemos las citas que no se pueden integrar en el texto de suerte que parezcan plagios». (Nuevos escolios ...o. c., p. 41). 
contradicciones sería operar con un modelo de lectura «hegeliano» que puede ser interesante como experimento filosófico, pero que no tiene por qué convertirse en imperativo para nadie, ni debe ser la única forma posible de interpretarlo.

\section{La antropología filosófica en la biblioteca de Gómez Dávila}

Como en ningún otro lugar de su obra, en Textos I Gómez Dávila aborda con profundidad y dedicada atención la problemática antropológica. Pero muy al estilo de sus contemporáneos, lo hace de una forma no tradicional, polemizando claramente con las aproximaciones metafísicas al problema del hombre usuales en Occidente. La obra de Gómez Dávila es otra prueba de cómo la problemática antropológica ha sacudido la filosofía occidental en el último siglo. Hace parte también del conjunto de aquellas filosofías que desde la aparición de la obra temprana de Martin Heidegger le han hecho eco a su crítica de la antropología filosófica tradicional como camino filosófico idóneo para afrontar la crisis de la metafísica en el mundo moderno.

Heidegger por supuesto no fue el único en abrir caminos de deconstrucción de la aproximación metafísica tradicional que le dieran una nueva oportunidad al pensamiento occidental en el siglo XX, obligando a un nuevo trato con la forma de escribir como vehículo de meditación profunda. Ortega y Gasset fue un adelantado en esa tarea con sus Meditaciones del Quijote de 1914, y la obra entera de María Zambrano y su pensamiento del exilio es otro ejemplo y síntoma de lo mismo: la necesidad de un pensamiento sin concesiones ante la amenaza permanente del nihilismo. En este sentido, Gómez Dávila es un pensador de su siglo.

En Textos I, Gómez Dávila aborda todos los temas centrales del debate antropológico contemporáneo que lo vinculan con la amplia tradición de pensamiento postmetafísico del siglo XX: la finitud, el tiempo y la muerte, las estructuras fundamentales de la condición humana como condición concreta, la experiencia de la conciencia y su desarrollo, el origen del hombre y la muerte de Dios, la filosofía de la historia y las convulsiones históricas de nuestra época. De modo particular, en Textos I, Gómez Dávila establece un diálogo con aquellas problemáticas antropológicas deconstruidas por Heidegger y asumidas abiertamente por Max Scheler, Ernst Cassirer, Helmuth Plessner u otros, sin hacer referencia directa a ninguno de esos autores, como era su costumbre.

La prueba de este diálogo no se encuentra solamente en los temas y argumentos desarrollados en Textos $I$, sino que se puede rastrear también en la biblioteca personal de Gómez Dávila, disponible en la Biblioteca Luis Ángel Arango de Bogotá, de la cual hasta el momento se han catalogado más de 16000 títulos ${ }^{17}$. Aunque es difícil saber el momento en el que Gómez Dávila adquirió

17 Además del catálogo del Fondo Gómez Dávila de la BLAA del Banco de la República disponible en línea en su sitio web, existe el inventario hecho por doña Rosa Emilia Gómez de Restrepo, hija de don Nicolás, divulgado por Michäel Rabier y disponible en línea en el sitio Bibliotecas de filósofos de la Scuola Normale Superiore di Pisa-Università degli Studi di Cagliari. 
muchos de sus libros, no existiendo certeza de que todas las ediciones previas a la fecha de publicación de Textos I (1959) disponibles en el catálogo hayan sido leídas por Gómez Dávila antes o durante la escritura de Textos I, y sin saber tampoco el momento exacto de composición de los ensayos, lo cierto es que la revisión de la Colección Gómez Dávila, que tanta fama le ha dado a Gómez Dávila como su obra, también nos da una pista clara de los intereses del filósofo colombiano en relacion con la problemática antropológica y en general con todo su pensamiento. La reconstrucción de un fragmento de la biblioteca «implícita» de Gómez Dávila detrás de su obra requiere mucho más que la enumeración de un catálogo ${ }^{18}$. Sin embargo, el catálogo de la Biblioteca es después de todo el «mapa» de los intereses del filósofo ${ }^{19}$.

En la Colección Gómez Dávila de la BLAA de Bogotá se encuentran prácticamente todos los títulos relevantes relacionados con la antropología filosófica del S.XX, predominantemente alemana y en su lengua original. Catalogados se encuentran 12 títulos de Scheler, la mayoría de ellos en ediciones de antes de 1959, incluyendo una edición de sus obras completas. De Cassirer hay 11 títulos, 10 de ellos ediciones previas a la fecha de publicación de Textos $I$, incluyendo la famosa edición en inglés del texto más popular de este filósofo alemán: An Essay on Man: an Introduction to a Philosophy of Human Culture (de 1947). De Helmuth Plessner hay dos títulos y de Arnold Gehlen tres, incluyendo el clásico Der Mensch: seine Natur und seine Stellung in der Welt (en la edición de 1962). Todo esto sin contar otros títulos relacionados con la problemática antropológica publicados antes de 1959 con los que contaba Gómez Dávila: los títulos en alemán de Otto Bollnow, Max Brod, Brenhard Groethuysen, Romano Guardini, Hans-Eduar Hengstenberg, Wilhelm Kamlah, Ludwig Klages, Theodor Litt, Rudolph Hermann Lotze, Erich Rothacker y Eduard Spranger; los títulos en inglés de Robin Collingwood, Ellis Havelock, Reinhold Niebuhr; y los títulos en francés de Pierre Cabanis, Paul Haeberlin y Chaerles Morazé.

De Martin Heidegger hay 17 títulos ${ }^{20}$ catologados en la Colección Gómez Dávila y 10 más sobre su filosofía. De estos últimos, sólo 5 títulos son ediciones previas al año 59, incluyendo el significativo texto de Karl Löwith Heidegger: Denker in Dürftiger Zeit (de 1953). De los textos de Heidegger, Gómez Dávila disponía al final de su vida 17 títulos, 15 en ediciones previas al 59. Entre ellos por supuesto están: Sein und Zeit (Tubinga: Niemeyer) y Uber den humanismus (Fráncfort del M.: Klostermann) en las ediciones de 1949, y Holzwege y Kant und das Problem der Metaphysik en las ediciones de Vittorio Klostermann de 1950 y 1951, respectivamente.

18 KInZeL, T., "Aphoristic Thought. The Problem of Reading and The Implicit Library» en: Gutiérrez, C. B., ed., Coloquio en el centenario de Don Nicolás Gómez Dávila (1913-2013), U. de los Andes, Bogotá, 2013, p. 25.

19 RaBier, M., «Un filósofo y su biblioteca: el fondo Nicolás Gómez Dávila más allá de su valor patrimonial» en: Boletín cultural y bibliográfico, Vol. XLIX, 89, 2015, p. 234.

2018 en el inventario de Rosa Emilia Gómez. 


\section{Cuestión de estilo}

En el diálogo de Gómez Dávila con la problemática filosófica contemporánea no sólo sobresalen el conjunto de temas y tesis desarrolladas en Textos I, sino también la forma particular como las desarrolla, distante del tratado, del sistema o de la obra científica, y más cercana al ensayo fenomenológico. Tomándose muy en serio el problema del hombre y su finitud, Gómez Dávila piensa en Textos I con la aguda precisión literaria del ensayo y en algunos momentos bordea incluso la poesía (en particular al final de cada uno de los ensayos).

Desde las primeras apariciones públicas de la obra de Gómez Dávila fue evidente para sus primeros lectores colombianos que la profundidad de su pensamiento estaba estrechamente asociada a las particularidades de su estilo: un estilo que ya se revelaba como único. En la presentación que hizo en 1955 para la revista Mito (Vol. 1, No. 4) de algunos escritos de Gómez Dávila, el ensayista colombiano Hernando Téllez (Bogotá, 1908-1966) ya calificaba su estilo como «Una confesión de tipo pascaliano acuñada en la fórmula literaria de La Bruyére» (pág. 210)²1.

Téllez es quizá el primero que pone en evidencia que el estilo de escritura fragmentaria y ensayística de Gómez Dávila lo vincula claramente con la tradición ensayística y moralistica, en particular la francesa, de la que era un cuidadoso lector también: Pascal, Montaigne, La Bruyére, La Rochefoucault y Joubert. En esta línea de interpertación destaca el trabajo seminal de Francia Elena Goenaga Trois moralistes: Marie Linage, Francois de La Rochefoucauld et Nicolás Gómez Dávila ${ }^{22}$.

Los textos que prologa Téllez en la revista Mito en 1955, cuatro años antes de la publicación de Textos $I$, aparecen bajo el nombre de «Notas» e incluyen, con algunas importantes variaciones, el texto completo del cuarto ensayo de Textos I (pp. 217-218 en la edición de Mito, y pp. 39-42 en la edición de Villegas) mas 106 escolios. Según Téllez, estos son fragmentos de lo que en ese momento iba ser el «segundo volumen de Notas» (la continuación del libro publicado en edición privada en México en 1954), que nunca se publicó, lo que prueba que en un momento crucial de la producción escrita de Gómez Dávila los apelativos de «notas», «textos» $\mathrm{y}$ «escolios» pudieron ser perfectamente intercambiables, y que ya desde antes de publicar Textos I, Gómez Dávila estaba escribiendo escolios.

21 Sobre la relación entre Gómez Dávila y Téllez véase: BARGuIL, N., El arabesco de la inteligencia: para una poética de Nicolás Gómez Dávila, Trabajo de grado, Pontificia Universidad Javeriana, Bogotá, 2013, pp. 23-25.

22 Goenaga-Olivares, F. E., Trois moralistes: Marie Linage, François de La Rochefoucauld et Nicolás Gómez Dávila, Tesis de doctorado, Universidad de París VIII, 2005-2006. Ver también: Goenaga-Olivares, F. E., La tumba habitada, Nicolás Gómez Dávila, el caso colombiano, Editorial Académica Española, Berlín, 2011, p. 26. Efrén Giraldo añade la posibilidad de compararlo con moralistas españoles como Gracián (GIRALDo, E., «Nicolás Gómez Dávila. La estética, el escolio y el ensayo» en: Revista Universidad de Antioquia, No. 314, 2013, p. 26). 
Junto a los más famosos escolios, Textos I también es la demostración del cultivo de un modo particular de hacer filosofía y escribirla que él mismo Gómez Dávila denomina «reaccionaria». Una forma de escribir filosofía que en Textos I evidencia aspectos que claramente permiten compararla también con la tradición fenomenológica del siglo XX y no solo con la moralística.

\section{La FenOMENOLOGía COMO MÉTOdo EN TeXtos I}

Es posible encontrar en Textos I una similitud estilística —esto es, metódicatanto con la fenomenología de raigambre husserliana como con la deconstrucción heideggeriana, esto es, con una fenomenología con vocación hermenéutica que está comprometida con afrontar cara a cara la amenaza del nihilismo.

Que las conclusiones de Gómez Dávila no coincidan con las de Husserl o Heidegger no nos debe confundir con respecto a la similitud en el proceder filosófico. Más que un asunto de «influencias» o de deudas intelectuales se trata de la forma de pensar las cosas. Si bien se ha insistido mucho que Gómez Dávila escribía sobre libros - y de ahí la importancia de su Biblioteca - la verdad es que era sobre todo un pensador de $\operatorname{cosas}^{23}$, como debe ser todo filósofo.

Hoyos Vásquez ${ }^{24}$ ha sopechado ya la influencia del Husserl de las lecciones de 1907 y sus reflexiones sobre la conciencia del tiempo inmanente en las reflexiones sobre el hombre, la filosofía y la temporalidad en Textos I. Un Gómez Dávila «enemigo de la especulación y partidario de lo concreto ${ }^{25}$ parece hacer una constante aplicación del lema husserliano de volver a las cosas mismas. En particular por su insistencia en hacer que la filosofía medite el lugar común ${ }^{26}$, tesis que defiende en el ensayo segundo de Textos I (pp. 17-19 edición de Villegas), donde expone su «manifiesto filosófico»: allí Gómez Dávila afirma que la salvaguarda de la filosofía es la meditación de los lugares comunes, pues estos «no formulan las verdades de cualquiera, sino los problemas de todos $»^{27}$. Hoyos además propone comparar el pensamiento reaccionario gomezdaviliano con la fenomenología puesto que ambos implican «una disposición intelectual y un ejercicio del pensamiento en el más auténtico sentido de la búsqueda de la realidad misma ${ }^{28}$.

A este argumento de Hoyos, quien siguiendo a Volpi vincula a Gómez Dávila con Husserl y Heidegger ${ }^{29}$, cabe añadir otros: la forma de abordar las temáticas antropológicas, el tono filosófico y el posicionamiento abiertamente

23 Saralegui, M., «Nicolás Gómez Dávila como crítico de la cultura hispánica» en: Ideas y valores, Vol. 65, No. 162, 2016, p. 317.

24 Hoyos, G., «Don Nicolás..., o. c., p. 1087.

25 Ib., p. 1087.

26 MeJíA, J. F., «Diálogo..., o. c., pp. 107-108.

27 Gómez Dávila, N., Textos I, o. c., p. 18.

28 Mejía, J. F., «Diálogo..., o. c., p. 109.

$29 \quad I b .$, p. 109. 
postmetafísico de sus reflexiones. Amalia Quevedo ya ha señalado por ejemplo el aspecto posmoderno de Gómez Dávila, quien consideraba la filosofía como un «género literario» ${ }^{30}$.

Textos I se manifiesta abiertamente como un ejercicio fenomenológico que sin embargo no se compromete en absoluto con tesis husserlianas o heideggerianas o con su vocabulario. Cuatro de los diez ensayos que componen Textos I despliegan una fenomenología de la conciencia y la condición humana: el tercero (pp. 21-36) sobre la conciencia que «acepta» o «rechaza» su condición concreta y finita, el quinto (pp. 45-53) sobre la antropogénesis en la insólita percepción de lo sagrado, el octavo (pp. 91-112) sobre la carne de la conciencia concreta que es opción, y el décimo ensayo (pp. 137-154) donde retoma la historia de la conciencia esta vez de cara a la vejez, la muerte y la nada como preámbulo a su platonismo y a su consecuente y ferviente declaración de la experiencia exultante de la encarnación y la eucaristía.

Si se examinan atentamente los otros ensayos se puede apreciar el despliegue de observaciones atentas de la modernidad (ensayos cuarto, pp. 39-42, y sexto, pp. 55-84), sobre la novela (ensayo séptimo, pp. 87-88), y sobre el hombre y la historia (ensayo noveno, pp. 115-135). Tales observaciones atentas constituyen una forma particular de fenomenología gomezdaviliana que recuerda el impacto que ha tenido este método filosófico en muchas filosofías del siglo XX.

En este orden de ideas, cabe desarrollar una lectura de Gómez Dávila como pensador postmetafísico, donde lo que más se destaca es la forma como asume las problemáticas filosóficas, las ideas y su tratamiento. En otras palabras, en Textos I no encontraríamos ninguna teoría, y si la hay, ésta es sólo un juego, que por mor de la argumentación, asume el ropaje de una reflexión sistemática.

Adicionalmente, el proyecto de reflexión ontológica de Gómez Dávila perfectamente puede ser leído en clave deconstructiva heideggeriana. El centro de ese proyecto de reflexión ontológica de fondo es la condición humana y su finitud, tema que ocupa buena parte de los ensayos primero, tercero, cuarto, quinto, octavo y décimo de Textos I. Todos estos hechos convierten al proceder fenomenológico y a la preocupación antropológica ${ }^{31}$, deriva inevitable de la ontología de cuño heideggeriano, en los ejes sobre los cuales se puede articular toda la diversidad de ensayos de Textos $I$.

30 Quevedo, A., El peso de la palabra, Medellín, Universidad Pontificia Bolivariana, 2007, pp. 29-30.

${ }^{31}$ Así lo ha reconocido César G. Cantón para otro caso: el de Hans Blumenberg, pues la vocación antropológica de su fenomenología metaforológica puede ser interpretada como una respuesta al reto planteado por Heidegger (González Cantón, C., «Blumenberg versus Heidegger: la metaforología como destino de la analítica existencial» en: Anuario Filosófico, XXXVIII, No. 83, 2005, pp. 725-746, y «La metaforología en Blumenberg como destino de la analítica existencial», Tesis doctoral de la Universidad Complutense de Madrid, Director Ramón Rodríguez García, Madrid, 2004). 


\section{El lugar del «CENTÓn Reaccionario» EN LA Obra de Gómez DÁvila}

Temáticamente sería una exageración afirmar que Textos I sólo es una respuesta a Ser y tiempo, por ejemplo. Prueba de esto último sería la discusión desarrollada por Gómez Dávila en uno de los ensayos más largos del conjunto que compone el libro, el ensayo sexto (pp. 55-84), conocido como el «centón reaccionario» (así lo denomina el mismo Gómez Dávila), y que algunos han querido considerlar como el ensayo «central» de su obra ${ }^{32}$, basados en el cuestionable y famoso comentario hecho por F. Pizano de Brigard, amigo cercano de Gómez Dávila, de que allí se encontraría el «texto implícito» al que estarían apelando los títulos de sus libros de escolios ${ }^{33}$.

En ese sexto ensayo, el filósofo bogotano formula una crítica a los proyectos políticos modernos entendiéndolos todos como la manifestación aparentemente variable de un mismo proyecto antropológico: intentar elevar al hombre a la condición de Dios, sin lograrlo. Toda política en el mundo moderno habría nacido de la misma matriz: una apuesta cultural de amplio y profundo alcance que sólo puede ser descrita como una religión, si se atiende al celo con el que se la practica y al fervor con el que se la defiende: la «religión democrática», un antropoteismo cuya doctrina teológica, dogmas y ritos el filósofo colombiano cuidadosamente describe. En este sentido, este ensayo constituye un momento importante del pensamiento político de Gómez Dávila al hacer explícita su crítica a los presupuestos teológicos y antropológicos de la visión de mundo «democrática» que define el mundo moderno. Pero, por la misma razón, el ensayo sexto es también un ejercicio crítico de las concepciones antropológicas de la modernidad que empata perfectamente con el hilo conductor de los otros ensayos de Textos $I$.

A pesar de lo que dijera Pizano de Brigard, el «centón reaccionario» no constituye el texto implícito al que alude el título de los libros de escolios. Los argumentos que se han expuesto para negar que el centon reaccionario es el texto implícito son varios y muy fuertes. Según Abad, Goenaga y Serrano ${ }^{34}$, los escolios se pueden entender en su mayor medida como comentarios a textos previamente leídos, o incluso también como citas intertextuales o plagios ocultos $^{35}$. Por lo que el texto implícito, ha afirmado Rabier, se puede identificar con la biblioteca personal de Gómez Dávila ${ }^{36}$, siendo su obra de escoliasta un

32 Hoyos, G., «Don Nicolás..., o. c.; Volpi, F., Nicolás..., o. c., p. 22.

33 Pizano de Brigard, F., "Semblanza de un colombiano universal: las claves de Nicolás Gómez Dávila», Revista del Colegio Mayor de Nuestra Señora del Rosario, 542, pp. 9-20, reeditado como Semblanza de un colombiano universal \& Conversaciones con Nicolás Gómez. Dávila, Universidad de los Andes, Bogotá, 2013).

34 Abad Torres, A., Pensar..., o. c., p. 30; Goenaga-Olivares, F. E., La pensée réactionnaire chez Gómez Dávila : mémoire, Tesis D. E. A., Universidad de Paris, 1997; Serrano RuIzCalderón, J. M., "Gnosticismo..., o. c., p. 368.

35 Rabier, M., «La cuestión..., o. c., pp. 31-35.

36 RABIER, M., «Biblioteca..., o. . . 
«metatexto» ${ }^{37}$, así exista, en palabras de Kinzel, una «biblioteca implícita» que supere al catálogo ${ }^{38}$. Por motivos idénticos, Goenaga Olivares y Serrano RuizCalderón han señalado que no se puede reducir la obra de Gómez Dávila a un comentario de la religión democrática ${ }^{39}$. Finalmente, Volpi ha afirmado, por ejemplo, que el texto implícito también puede ser la obra ideal — tan solo imaginada- de Gómez Dávila ${ }^{40}$. Para Abad y Serrano Ruiz-Calderón el texto implícito puede ser la tradición occidental ${ }^{41}$, y para Goenaga el texto implícito es Dios ${ }^{42}$.

Más que ser el centro de toda su obra, el «centón reaccionario» responde, como otros ensayos de Textos I, a la necesidad de pensar la problemática condición del hombre abierta en la modernidad. En particular, en ese ensayo, Gómez Dávila considera críticamente la posición antropológica moderna. Sin embargo, a lo largo de Textos I, Gómez Dávila reconoce que el problema antropológico abierto de forma tan dramática en el mundo moderno no es una mera circunstancia histórica, una mera «situación», o un problema de época, sino una realidad consubstancial a la existencia humana misma. Como Heidegger, Gómez Dávila sabe que el problema del hombre contemporáneo no se agota en las trasformaciones culturales de la modernidad, sino que la modernidad con todos sus desafueros es a fin de cuentas otro síntoma más del drama humano; eso sí, quizá el capítulo más triste o ridículo —según sea el punto de vista— de su larga comedia.

\section{La antropología filosófica como tema en TeXtos I. Aceptación o Rechazo de LA CONDICIÓN HUMANA CONCRETA}

Previo al centón reaccionario y su crítica feroz de la debacle antropoteísta moderna, desarrollada con las mismas armas de la «sociología de la religión» de la época, en el ensayo cuarto (pp. 39-42) de Textos I (publicado previamente en la revista Mito) Gómez Dávila critica la actitud moderna ante la muerte, su irrespeto por la frontera entre lo sagrado y lo profano y su vano afán por naturalizarla y convertirla en una asunto técnico administrable. El hecho de que para Gómez Dávila el hombre moderno no le ponga la cara a la muerte y se disponga a ocultarla mediante la técnica, emparenta abiertamente sus

37 Rabier, M., «Un filósofo..., o. c., pág. 234.

38 Kinzel, T., «Aphoristic..., o. c., pág. 25.

39 Goenaga-Olivares, F. E., La tumba..., o. c., pp. 30-31; Serrano Ruiz-Calderón, J. M., «Gnosticismo..., o. c., p. 368; Serrano Ruiz-Calderón, J. M., «El comentario a la religión democrática en Gómez Dávila» en: Urbanek, K., ed., Prawdziwy reakcjonista. Nicolásowi Gómezowi Dávili w stulecie urodzin, Furta Sacra, Varsovia, 2013, p. 59.

40 Volpi, F., Nicolás..., o. c., p. 33.

41 Abad Torres, A., Pensar..., o. c., pág. 30; Serrano Ruiz-Calderón, J. M., «El comentario..., o. $c$.

42 Goenaga-Olivares, F. E., La tumba..., o. c., pp. 30-31. 
reflexiones antropológicas con Ser y tiempo. Pero sobre todo es una señal del proceder gomezdaviliano en Textos $I$ : la descripción pausada de síntomas modernos o no- de la fractura humana, del fracaso humano, incluyendo la forma particular que este asume en la modernidad.

A la descripción del modo moderno de ser ante la muerte (ensayo cuarto) y de la religión democrática, con sus dogmas y tenebrosos ritos (en el «centón reaccionario»), se le suma una descripción de la novela moderna en el ensayo séptimo como símbolo contemporáneo de la aceptación de nuestra finitud. Los temas de los ensayos de Textos I van así pivotando uno a uno en torno al problema de la aceptación o el rechazo de la condición humana, tema que Gómez Dávila desarrolla abiertamente en el ensayo tercero (pp. 21-36), en el corazón del ensayo octavo (pp. 91-112) y en el poético ensayo décimo (pp. 137-154) en el que expone la historia (fenomenología) de la conciencia de la aceptación, que culmina en un reconocimiento apasionado de la verdad del platonismo.

El rechazo de nuestra condición es la vocación del hombre moderno y la causa de su ignorancia y su dolor ${ }^{43}$, y por eso la modernidad en sus múltiples facetas es otro síntoma de nuestra finitud ${ }^{44}$. $\mathrm{Al}$ rechazo se opone la aceptación viril y lúcida de nuestra condición humana ${ }^{45}$. La aceptación es característica del pensamiento reaccionario, a la que tiende con erotismo platónico gómezdávila en Textos I sin lograrla plenamente, pues de modo consecuente con su tesis antropológica central, todo asomo de aceptación es fugaz y nos recuerda que nuestra condición esencial es el fracaso. Sólo que la aceptación del fracaso ocurre justamente cuando logramos vivir la realidad de la idea en la carne del deseo, o la presencia en la ausencia, como enseña el platonismo del ensayo décimo, el último de Textos $I$.

Antropológicamente hablando el tercero es un ensayo central, pues Gómez Dávila toma distancia de todas las antropologías tradicionales para proponer una en la que la condición humana no es el punto de llegada del análisis filosófico, sino el punto de partida opaco e indisoluble de toda posible comprensión. Inicia con ello su fenomenología de la finitud descargándose de los compromisos ontológicos propios tanto de las metafísicas medievales como de las metafísicas modernas de la subjetividad.

El hombre es su stituación concreta y nada más, afirma Gómez Dávila ${ }^{46}$, poniendo en cuestión al mismo tiempo el dualismo metafísico tradicional alma/cuerpo como la distinción moderna entre sujeto y objeto.

Incluso invita a que ahondemos en la comprensión heideggeriana de la existencia y no interpretemos superficialmente la configuración metafórica «ser-en-el-mundo»:

«No basta, luego, con decir que el hombre se halla arrojado en una situación irresoluble, que está inserto en ella, dado en ella, en ella inmerso. Es menester

\footnotetext{
43 Gómez Dávila, N., Textos $I$, o. c., pp. 32-36.

$44 \quad I b .$, pp. 39-42, 52-53, 83-84, 110-112.

$45 \quad I b .$, pp. $12-14,32-36,39-42,84,88,137-154$.

$46 I b .$, pp. 22 y ss.
} 
repetir con ahínco que el hombre es su situación, su situación total, y su situación nada más.

La situación del hombre no es, luego, una configuración externa de acontecimientos donde el hombre fortuitamente se halla, sino la condición misma del hombre; el hombre no es una esencia pura sometida a una impura y ajena condición, el hombre es la impureza misma de la condición humana.

El hombre es su condición, su condición quebrada y rota» ${ }^{47}$.

Semejante condición "quebrada y rota» es la de un movimiento oscilante, entre la "quimera» y el «hastío», entre el no conseguir lo que se desea y el no satisfacerse con lo que se consigue. Por ello, «la condición del hombre es el fracaso», "es impotencia», y "ser hombre es no lograr» ${ }^{48}$. A esta tesis le sigue una fenomenología del tiempo y de la conciencia. Con ella se revela que el tiempo no es condición de posibilidad sino síntoma de la condición humana del fracaso, a la vez que la conciencia es el modo como ésta se realiza: la «conciencia es la existencia quebrada en condición humana», por lo que la «conciencia es conciencia de la condición del hombre» ${ }^{49}$.

\section{LA FRONTERA ENTRE LO HUMANO Y LO INHUMANO}

La tesis del fracaso abre de modo particular Textos I. En el ensayo primero, Gómez Dávila enuncia su metafísica de la libertad en clave antropológica. Puesto que el tiempo tiene un sentido irreparable (tesis que amplía en el ensayo tercero $)^{50}$, la libertad humana es liberdad de errar. Semejante factum dictamina nuestra distinción antropológica, esto es, la frontera entre el hombre y lo vivo y lo material, entre lo humano y lo inhumano:

«La libertad es nuestro riesgo, el noble privilegio de incumplir nuestro deber. El animal avanza, imperturbable, hacia la plenitud de su esencia; la materia la realiza con su existencia sola. El hombre se estremece y oscila al borde de sí mismo. Nunca es blanco donde vibra la flecha clavada; sino aguda flecha en el viento» ${ }^{51}$.

La frontera entre lo humano y lo animal, tema central de la antropología filosófica, es también tema del ensayo cuarto en el que Gómez Dávila expone y cuestiona la supresión moderna del escándalo de la muerte, contraponiendo la muerte de Sócrates y la de Cristo en la Cruz, al Holocausto ${ }^{52}$.

$47 \quad I b .$, p. 23.

$48 I b .$, p. 24.

$49 \quad I b .$, p. 27.

so Ib., pp. 24-26.

$51 \quad I b .$, pp. 13-14.

52 «Al anciano prisionero que dialoga en la mañana luminosa y fúnebre, a la nocturna angustia de sudor y de sangre, el orgullo moderno mostrará grupos sumidos en pavura y espanto que las ametralladoras, en hilera, encausan hacia los hornos crematorios». Ib., p. 42. 
La diferencia antropológica ambién aparece como tema en el ensayo quinto, en el que hay un patente diálogo con Nietzsche que se enuncia desde la primera frase: «Entre el nacimiento de Dios y su muerte se desarrolla la historia del hombre ${ }^{53}$. El primer paso que da Gómez Dávila es vincular la antropogénesis a la teogénesis: el hombre nace cuando se hace posesor de la insólita evidencia de lo sagrado, por lo que la «elaboración tenaz de su experiencia religiosa ha sido la empresa milenaria del hombre» ${ }^{54}$. En un segundo paso devela la fuente de toda posible grandeza en medio de la finitud humana: la evidencia de los valores. Es su platonismo ${ }^{55}$ el que le permite contraponer a Nietzsche las últimas líneas irónicas de este ensayo, en las que se afirma que la pérdida de Dios implicará el retorno del hombre a la penumbra animal ${ }^{56}$.

\section{Metafísica de los VAlORES Y FILOSOFÍA DE LA HISTORIA}

El ensayo octavo vincula abiertamente la crítica de la modernidad y de la cultura con el ejercicio de fenomenología de la conciencia y las tesis antropologógicas. Quizá es el ensayo donde se evidencia con mayor claridad la estructura argumentativa de Textos I y donde se hace también patente que cada ensayo es un intento nuevo, como una segunda navegación, de acceder a la misma demostración.

La fenomenología de la conciencia en el ensayo octavo es pausada. Le toma a Gómez Dávila unas 8 páginas describir el proceso que da paso de la cotinaneidad sometida a empresas serviles hasta su metafísica de la libertad como opción concreta. Esto es así porque Gómez Dávila da cada paso de esta historia abordando una discusión antropológica de largo aliento. Así como en ensayos previos habia trazado la frontera que distingue lo humano en la obligación de errar (ensayo primero), en la conciencia del fracaso (ensayo III), en el escándalo de la muerte (ensayo cuarto), en la experiencia de lo divino (ensayo quinto), en el ensayo octavo Gómez Dávila profundiza la frontera trazada exponiendo los testimonios del fracaso, como contracara de la presencia inequívoca de los valores.

Intentando un argumento trascendental, Gómez Dávila no cesa de recabar en el a priori del fracaso: la inequívoca presencia de los valores, tema sobre el que vuelve en las páginas platónicas del ensayo décimo. Esto le permite a Gómez Dávila anteponer una metafísica axiológica a una metafísica

$53 \quad I b .$, p. 45.

$54 \quad I b .$, p. 50.

55 Es a partir de la evidencia axiológica de la verdad, el bien y la belleza, evidencia que otorga la experiencia religiosa, como el hombre se sacude de las limitaciones de su experiencia animal del mundo $I b$., p. 51.

56 La evidencia axiológica que otorga la experiencia religiosa es sin embargo frágil, y al morir Dios, se asoma el peligro de que «el hombre surgido en las lontananzas pliocenas» pueda «sumergirse en el vasto océano animal». Ib., p. 52. 
meramente lógica o de la necesidad. El ser es opción antes que materia y es, además opción concreta ${ }^{57}$. La historia no supone por ello al universo sino al revés ${ }^{58}$. Por lo que la «totalidad del ser inmanente se escalona en una gradación de libertades ${ }^{59}$.

En el ensayo octavo Gómez Dávila intenta una gradación cuasineoplatonica del $\operatorname{ser}^{60}$ (pág. 100 y ss.): nos lleva de la materia, al animal, y de allí a la consciencia de sí y a la experiencia de los valores, como preámbulo de la civilización, la cultura y la alienación del hombre. Una alienación que en el mundo moderno se hace patente con un énfasis particular, pero que no se reduce a él. Cada momento de esta gradación es esencialmente diferente al otro e implica un salto, nunca una evolución, algo que también sostiene en el ensayo primero ${ }^{61}$ (pág. 13) y en el ensayo quinto ${ }^{62}$ (pp. 45-50): ser hombre es un «salto» en el ser.

Con esta crítica de las metafísicas tradicionales dualistas o monistas Gómez Dávila nos recuerda que los graves problemas del hombre moderno no se reducen a una cuestión de época o a una situación «superable». Gómez Dávila no es un gnóstico, sino más bien un anti-gnóstico ${ }^{63}$, aunque según Gómez Dávila la religión democrática que define la teología de la modernidad no sea estrictamente hablando "gnosticismo» ${ }^{64}$.

Finalmente, el ensayo noveno (pp. 115-135) expone la filosofía de la historia de Gómez Dávila, clara derivación de las tesis del ensayo octavo. Allí Gómez Dávila desarrolla una verdadera crítica de la razón histórica, establece las condiciones de posibilidad a priori de la comprensión histórica y devela los resortes íntimos de la «filosofía de la historia» que él mismo propone y se hace carne en el centón reaccionario: un «esquema orgánico» de comprensión histórica o tradición viva, que tiene un solo nombre: «Iglesia» ${ }^{65}$.

$57 \quad I b .$, p. 99.

$58 \quad I b .$, p. 97.

$59 \quad I b .$, p. 100.

$60 \quad I b .$, p. 100 y ss

$61 \quad I b .$, p. 13.

$62 \quad I b .$, pp. $45-50$

63 Abad Torres, A., «Nicolás Gómez Dávila y las raíces gnósticas de la modernidad»en: Ideas y valores, no. 142, 2009, pp. 131-140.

${ }_{64}$ Mientras que las cosmogonías órficas y las sectas gnósticas son para Gómez Dávila antropoteismos retrospectivos (el hombre es un dios caído) y dualismos sombríos, «la moderna religión democrática es un antropoteismo futurista» y un «monismo jubiloso», y, por lo mismo, una «doctrina de una teogonía dolorosa», pues en ella el hombre es un «dios que la materia levanta como su grito de victoria», el hombre es "arcilla de su condición futura» (Gómez Dávila, N., Textos I, o. c., pp. 63-64). Sobre este punto en particular, en el marco de una discusión ampliada sobre el gnosticismo de la modernidad, ver: ToRREgroza, E., La nave ...o.c., p. 285.

65 Gómez Dávila, N., Textos I, o. c., pp. 131-135. 


\section{CONCLUSIONES HERMENÉUticAS}

Las referencias constantes de Gómez Dávila a su propia tarea y actividad de escritor y pensador ${ }^{66}$, en las que no calla su escepticismo con respecto al impacto y resultado de su obra, y donde no oculta nunca sus limitaciones y condiciones de posibilidad históricas, más que ser prueba suficiente de una elogiable «modestia» intelectual, son prueba sobre todo de la conciencia crítica y metodológica de un autor que no quiere ser atrapado en una casilla, y que quiere más bien invitar al lector a que mire lo señalado antes que quedarse mirando a quien lo señala.

A punta de textos breves, paridos como conquistas sutiles en medio de la comedia humana, el filósofo bogotano no habría hecho sino intentar lo que otros pensadores también habrían hecho: combatir el sinsentido y la debacle humana, mediante la experiencia de vivir sus preguntas metafísicas, pues, como señala uno de sus escolios: «Los problemas metafísicos no acosan al hombre para que los resuelva, sino para que los viva ${ }^{67}$.

Problematizando el ser filósofo, el ser escritor, el acto de pensar y escribir, pero también, junto a ello, el acto de leer, ese lector y espectador del mundo que fue Gómez Dávila nos habría enseñado una serie de caminos posibles de interpretación de la condición humana, una hermenéutica vital, esto es, una hermenéutica de la vida para la vida, pues su obra es a fin de cuentas también una hermenéutica que hizo posible una vida.

La obra de Gómez Dávila es muy diversa, filosóficamente hablando, y no admite un único tipo de lectura. Navega una gran variedad de temas y no sólo los diversos campos de reflexión filosófica. En sus breves ensayos y escolios encontramos más el planteamiento de problemas filosóficos, tensiones conceptuales e intentos de reflexión, que soluciones cabales. El conjunto de su obra es un verdadero reto para la interpretación filosófica, por la forma cómo está escrita —su particular y provocador estilo- y por el tipo de inquietudes que formula, los conceptos y metáforas que pone en funcionamiento y las hipótesis que lanza al aire como una aguda provocación. Una obra así invita, como cualquier producción humana creativa y compleja al examen pausado y atento, a la consideración detenida de aspectos puntuales de los distintos momentos de su pensamiento.

No hay ningún error hermenéutico por tanto en desentenderse de la imagen -o del mito- de una sola forma de pensar «gomezdaviliana», de un solo bloque de posturas articuladas y coherentes bajo el nombre propio "Gómez Dávila». Si se descubre algo así, será con seguridad más la creación de ese particular lector, que es capaz de consumar una tarea en la que el mismo Gómez Dávila nunca se empeñó: hacer un «sistema filosófico».

66 Por ejemplo en Textos I, o. c., pp. 55-56, o en Notas, o. c., pp. 43, 49, 50, 51, 173, 316 y 439.

67 Gómez dávila, N., Nuevos escolios ... o. c., Tomo I, p. 56. 
Un pensamiento fragmentario, una filosofía hecha textos breves y escolios, obliga a una interpretación que diferencie los momentos de escritura y que, sin dejar de establecer vínculos con otros momentos de una escritura cobijada bajo el mismo nombre propio, nos conduzca más allá del mito del «autor originario» y el "pensamiento último», hasta encontrar el lugar propicio para el replanteamiento sugerente de problemáticas filosóficas.

La filosofía suele navegar en las aguas profundas de la inquietud así quiera por vocación aposentarse en la comodidad de un puerto seguro. Si bien el anhelo de seguridad constituye su meta más anhelada, el filósofo es más un buscador que un poseedor de evidencias. Por ello el mayor logro de una filosofía es conquistar la sabiduría del navegante: aquel regalo que otorga la experiencia recurrente de nadar en aguas turbulentas aprendiendo el difícil arte de no ahogarse.

La obra de un filósofo se caracteriza más por los problemas que plantea que por las respuestas que formula. Dicho de otra forma: las respuestas en la obra del filósofo suelen ser más los trazos del camino andado, el recuento de una bitácora, que el tesoro propiamente buscado. Nicolás Gómez Dávila era plenamente consciente de ello si entendemos el título de su obra más extensa y famosa «Escolios a un texto implícito» como la descripción de un proceso en el que cada escolio hace parte de la andadura de un camino cuya meta nunca se hace al final explícita, porque por principio trasciende el ejercicio de escritura filosófica. Los «escolios», junto con las otras formas fragmentarias de escritura que caraterizan la obra del filósofo bogotano, las «notas» y los «textos» pueden ser interpretados por ello mismo como indicios de una dificultad, el recuerdo de una tensión, una estela en la ruta que recuerda la inminente presencia de un abismo. O simplemente, como ocurre en muchos casos, las anotaciones de un viajero, un observador agudo que no escatima la sensibilidad poética o el sentido del humor.

\section{BiBLIOGRAFÍA}

Abad Torres, A. (2008). Pensar lo implícito: en torno a Gómez Dávila. CRIE, Pereira.

Abad Torres, A. (2009). «Nicolás Gómez Dávila y las raíces gnósticas de la modernidad». $\mathrm{Y}$ en: Ideas y valores, no. 142.

Barguil, N. (2013). El arabesco de la inteligencia: para una poética de Nicolás Gómez Dávila, Trabajo de grado. Bogotá: Pontificia Universidad Javeriana.

Billé, Ph., ed. (2003). Studia daviliana, edición del autor, La Croix Comtesse.

Goenaga-Olivares, F. E., Trois moralistes: Marie Linage, François de La Rochefoucauld et Nicolás Gómez Dávila. Tesis de doctorado, Universidad de París VIII, 2005-2006.

Giraldo, E. (2013). «Nicolás Gómez Dávila. La estética, el escolio y el ensayo». Y en: Revista Universidad de Antioquia, No. 314.

Goenaga-Olivares, F. E. (1997). La pensée réactionnaire chez Gómez Dávila: mémoire, Tesis D.E.A., Universidad de Paris.

Goenaga-Olivares, F. E. (2011). La tumba habitada, Nicolás Gómez Dávila, el caso colombiano. Berlín: Editorial Académica Española. 
Gómez Dávila, N. «El reaccionario auténtico». Y en: Revista de la Universidad de Antioquia, No. 240, 1995, pp. 16-19.

Gómez Dávila, N. (2002). Textos I. Bogotá: Villegas.

Gómez Dávila, N.(2003). Notas. Bogotá: Villegas.

Gómez Dávila, N. (2005). Escolios a un texto implícito. Bogotá: Villegas. 2 tomos.

Gómez Dávila, N. (2005). Nuevos escolios a un texto implícito. Bogotá: Villegas. 2 tomos.

Gómez Dávila, N. (2005). Sucesivos escolios a un texto implícito. Bogotá: Villegas. 2 tomos.

Hoyos, G. (2008). «Don Nicolás Gómez Dávila, pensador en español y reaccionario auténtico». Y en: Arbor, No. 734, pp. 1085-1100.

Kinzel, T. (2013). "Aphoristic Thought. The Problem of Reading and The Implicit Library». Y en: Gutiérrez, C. B., ed., Coloquio en el centenario de Don Nicolás Gómez Dávila (1913-2013). Bogotá: U. de los Andes.

Mejía, J. F. (2013). Diálogo entre un demócrata y un reaccionario: Guillermo Hoyos Vásquez y su lectura fenomenológica de Nicolás Gómez Dávila». Y en: Universitas Philosophica, No. 61, p. 105.

Pizano de Brigard, F. (2013). Semblanza de un colombiano universal \& Conversaciones con Nicolás Gómez Dávila. Bogotá: Universidad de los Andes.

Quevedo, A. (2007). El peso de la palabra. Medellín: Universidad Pontificia Bolivariana.

Rabier, M.(2013). «Biblioteca gomezdaviliana: las fuentes bibliográficas del pensamiento de Nicolás Gómez Dávila». Y en: Revista interamericana de bibliotecología, Vol. 36, no. 3.

Rabier, M. (2014). «La cuestión literaria en la obra de Nicolás Gómez Dávila». Y en: Perifrasis, No.10.

Rabier, M. (2015). «Un filósofo y su biblioteca: el fondo Nicolás Gómez Dávila más allá de su valor patrimonial». Y en: Boletín cultural y bibliográfico, Vol. XLIX, 89.

Saralegui, M. (2016). «Nicolás Gómez Dávila como crítico de la cultura hispánica» en: Ideas y valores, Vol. 65, No. 162.

Serrano Ruiz-Calderón, J. M. (2013). «Gnosticismo y religión democrática». Y en: Anuario de Derecho Eclesiástico del Estado, XXIX, p. 366.

Serrano Ruiz-Calderón, J. M. (2013). «El comentario a la religión democrática en Gómez Dávila». Y en: Urbanek, K., ed., Prawdziwy reakcjonista. Nicolásowi Gómezowi Dávili $w$ stulecie urodzin. Varsovia: Furta Sacra, Varsovia.

Torregroza, E. (2014). La nave que somos: hacia una filosofía del sentido del hombre. Bogotá: Pontificia Universidad Javeriana.

Volpi, F. (2005). Nicolás Gómez Dávila. El solitario de Dios. Bogotá: Villegas.

Universidad del Rosario

ENVER TORREgrozA LARA

Bogotá, Colombia

enverj.torregroza@urosario.edu.co

[Artículo aprobado para publicación en enero de 2018] 